\title{
Efficiency of Logistic Industry of Hunan based on DEA
}

\author{
Zhao zhongping \\ School of Management, Hunan University of Commerce, China. PR \\ zzp256@126.com
}

Keywords: efficiency of logistic industry; logistic industry of Hunan, DEA

\begin{abstract}
The logistics industry is a new economic growth point to promote regional economic development. This paper analyzes the logistical efficiency of eight areas in Hunan province from 2005 to 2014 using the BCC model and CCR in DEA analysis. The results show that both the PTE and SE of the logistics industry are low. We should enhance the logistic technology and decrease the logistic scale to improve the efficiency of Logistic Industry of Hunan.
\end{abstract}

\section{Introduction}

With the economic fast development and the process of globalization, logistics industry as an emerging industry has become an important part of the modern economy and an important growth point and accelerator of China's economic development. In the promotion of regional resources optimal allocation, improve the investment environment and increase the competitive advantage of industry, regulating the equilibrium of supply and demand of the market, promote the quality of economic operation and enhance the comprehensive strength of area, the logistics industry plays an important role. Therefore, the efficiency of logistics industry is not only related to the development of the logistics industry, but also to a large extent determines the speed of regional economic development. The so-called logistics industry efficiency refers to the effective use of the logistics resources, is the logistics industry market competition ability, input output capacity and sustainable development capacity of the general term. The research from different aspects of the logistics industry efficiency evaluation of the problem, but specifically for the logistics industry in Hunan Province, the development efficiency of the research is not seen in the domestic literature. The DEA analysis method, through the research on the logistics industry in Hunan Province efficiency and its influencing factors, explore the logistics industry to enhance the path and strategy of development, both to provide theoretical support and data support for the formulation of the relevant management departments in Hunan Province logistics industry development strategy. At the same time, it can provide a reference for the similar areas of logistics industry development.

\section{Principles and Models of DEA}

\section{Principles of DEA}

This paper uses DEA (Envelopment Analysis Data) to study the efficiency of Hunan logistics industry. DEA is founded by Charles A, Cooper WW and Rhodes in 1978. The method is mainly used for evaluation of a plurality of the same type with the relative efficiency of multiple inputs and multiple output decision making DMU (Decision Making Units). Based on the input and output data of DEA, the relative efficiency of each decision unit is calculated by using linear programming. If the efficiency value is 1 , the decision unit DEA is effective, if the efficiency value is between 0 and 1 , the DEA is invalid. The efficiency value is close to 0 , the higher the degree of invalid. For the non-effective unit, we can use the projection analysis to get the specific adjustment quantity, and provide the quantitative decision-making basis for the decision maker. DEA avoids the subjectivity of the weight given by the human, and is based on the objective data. Through the linear programming, the efficiency value of the decision units is obtained. 


\section{CCR Model}

The most basic model of DEA is the CCR model. It is assumed that the scale of remuneration is fixed, so as to calculate the relative comprehensive technical efficiency. If there are $\mathrm{n}$ decision making units, $m$ input variables for each decision unit, and $\mathrm{p}$ output variables.

$X_{j}=\left(x_{1 j}, x_{2 j}, \ldots, x_{m j}\right)^{T} j=1,2, \ldots n$ and $Y_{j}=\left(y_{1 j}, y_{2 j}, \ldots, y_{m j}\right)^{T} j=1,2, \ldots n$ are input variables and output variables for decision making unit DMU. CCR model is described as follows:

$$
\text { s.t. }\left\{\begin{array}{l}
\sum_{j=1}^{n} \lambda_{j} X_{j}+s^{-}=\theta X_{0} \\
\sum_{j=1}^{n} \lambda_{j} y_{j}-s^{+}=y_{0} \\
S^{-} \geq 0, s^{+} \geq 0, \lambda_{j} \geq 0, \\
\theta
\end{array}\right.
$$

The optimal design of the solutions for the lambda *, $\mathrm{s}^{*-}, \mathrm{s}^{*+}, \theta^{*}$, are as follows:

(1) if $\theta^{*}=1$ and $s^{*}=s^{*+}=0$, theta, DMU DEA. Technology is effective, and the scale is effective, the decision unit has reached the best combination and the maximum output;

(2) if $\theta^{*}=1$, and $s^{*}$, $s^{*+}$ is 0 , then DMU is weak DEA efficiency. At this time, the decision-making unit or technology is invalid, or the scale is invalid;

(3) if $\theta^{*}<10$, DEA is invalid.

\section{BCC Model}

The CCR model assumes that the scale of the decision making unit is constant, that is, the size of the decision making unit is not affected by its efficiency. In fact, the scale of the change will lead to changes in the efficiency of the decision-making unit. Increase investment may not be the same as the increase in output. The production efficiency, which is influenced by the scale factor, is called the scale efficiency. CCR model in returns to scale invariant under the assumption, the optimal value of $\theta^{*}$ the comprehensive technical efficiency, it depends on decision making unit resources disposition ability, the efficient use of resources and capacity of comprehensive measurement and evaluation. Comprehensive technical efficiency can be decomposed into pure technical efficiency and scale efficiency. Pure technical efficiency reflects the factors that affect the efficiency of decision making units due to the management and technology, and the scale efficiency is the production efficiency of the scale factor.

\section{Empirical research of Logistic Industry of Hunan}

\section{Selection of Index System}

Logistics is a complex system of multi input and multi output. The input index and output index of the efficiency analysis of the logistics industry should follow the principle of the representative and the principle of the output. In this paper, a comprehensive literature, select the logistics practitioners, the number of $\mathrm{x} 1$, logistics mileage number $\mathrm{x} 2$ and logistics industry fixed assets investment X3 as input indicators, which respectively represent the logistics industry manpower, material and financial resources, the three factors of production inputs. In this paper, we select the output value of the logistics industry, Y1, Y2 and Y3 for the logistics industry. Logistics industry output value Y1 reflects the economic benefits of the logistics industry, the freight volume Y2 and the turnover of goods Y3 is reflected in the logistics industry output of social benefits.

\section{Acquisition of Raw Data}

The following data are taken from the China Statistical Yearbook. Some directly from the China Statistical Yearbook, such as the logistics industry fixed asset investment X3, the logistics industry output value Y1, freight volume Y2 and cargo turnover Y3. Some of the data is calculated based on 
the China Statistical Yearbook in the original data processing, such as logistics industry practitioners X1 and logistics mileage X2.

Table 1 Raw data of Logistic Industry of Hunan

\begin{tabular}{|l|r|r|r|r|r|r|}
\hline index name & $\begin{array}{l}\text { value of } \\
\text { logistic }\end{array}$ & $\begin{array}{l}\text { freight } \\
\text { volumes }\end{array}$ & $\begin{array}{l}\text { freight } \\
\text { turnover }\end{array}$ & \multicolumn{1}{l|}{$\begin{array}{l}\text { employee } \\
\text { number }\end{array}$} & mileage & \multicolumn{1}{l}{$\begin{array}{l}\text { fixed } \\
\text { assets }\end{array}$} \\
\hline unit & \multicolumn{1}{|c|}{$10^{8}$ Yuan } & $10^{4}$ ton & $10^{8}$ ton.km & 1 & $\mathrm{~km}$ & $10^{8}$ Yuan \\
\hline variable & Y1 & \multicolumn{1}{|c|}{ Y2 } & Y3 & X1 & X2 & X3 \\
\hline 2005 & 550 & 45367 & 2361 & 90904 & 57882 & 378 \\
\hline 2006 & 688 & 56708 & 2951 & 113630 & 72353 & 473 \\
\hline 2007 & 859 & 70885 & 3689 & 142038 & 90441 & 591 \\
\hline 2008 & 1074 & 88607 & 4612 & 177547 & 113051 & 739 \\
\hline 2009 & 1343 & 110759 & 5765 & 221934 & 141314 & 923 \\
\hline 2010 & 1492 & 123065 & 6405 & 246593 & 157015 & 1026 \\
\hline 2011 & 1746 & 156596 & 8071 & 242590 & 159260 & 1521 \\
\hline 2012 & 2046 & 189799 & 9630 & 236101 & 162136 & 1433 \\
\hline 2013 & 2213 & 219130 & 10605 & 243019 & 168675 & 1543 \\
\hline 2014 & 2378 & 198009 & 11674 & 275895 & 180748 & 2124 \\
\hline
\end{tabular}

\section{Obtainment of Operation Results}

This paper calculates the technology efficiency, pure technical efficiency and scale efficiency of logistics industry of Hunan province from 2014 to 2005. The operation software is DEAP2.1, and the models are BCC and CCR. The results are showed in the Table 2.

Table 2 the Operation Results of DEA

\begin{tabular}{|c|c|c|c|c|}
\hline & TE & PTE & SE & SR \\
\hline 2005 & 0.633 & 0.744 & 0.851 & irs \\
\hline 2006 & 0.787 & 0.796 & 0.989 & irs \\
\hline 2007 & 1 & 1 & 1 & - \\
\hline 2008 & 0.89 & 0.899 & 0.989 & drs \\
\hline 2009 & 0.982 & 1 & 0.982 & drs \\
\hline 2010 & 0.817 & 0.821 & 0.995 & drs \\
\hline 2011 & 0.796 & 0.889 & 0.895 & drs \\
\hline 2012 & 0.879 & 0.883 & 0.996 & drs \\
\hline 2013 & 0.808 & 1 & 0.808 & drs \\
\hline 2014 & 0.835 & 0.969 & 0.862 & drs \\
\hline
\end{tabular}

\section{Results Analysis and Related Suggestions}

\section{Technology Efficiency}

There is a big fluctuation in logistics industry in Hunan province from 2005 to 2014. The minimum technology efficiency is 0.633 , the maximum is 1 , and the average value is 0.842 . The development of logistics industry is necessary. But it's not correct to ignore the actual situation of Hunan economy and blind pursuit of the size of the logistics industry expansion. Logistics industry management level, mode of operation is relatively backward, is prone to invest resources utilization rate is not high, the output is insufficient, deviate from the inputs and outputs the best matching state.

\section{Pure Technology Efficiency}

The technical efficiency of logistics is mainly caused by two aspects, which are pure technical efficiency and scale efficiency. From the pure technical efficiency, the maximum value of 1 , and the minimum value of 0.733 . In general, in recent years, the logistics industry in Hunan Province, the 
pure technical efficiency has been improved. Hunan province should further open up the logistics network, logistics nodes, the introduction of logistics personnel and technology to improve the pure technical efficiency of logistics.

Scale Efficiency and Scale Return

In terms of scale efficiency, except for 2007 to reach peak 1, the rest are less than 1. Especially since2008, the scale efficiency of logistics has been decreasing year by year. From the point of view of the scale, the scale of income in 2007 before the growth stage, and after 2008, the scale of income has been in decline stage. Changes in the scale of income show that the scale of logistics in Hunan province has exceeded the actual needs. The logistic scale should be moderately cut. On the one hand, it's necessary to ban logistics base, logistics centers and other large logistics infrastructure construction in Hunan; on the other hand, we should ease parts of the logistics center to other province in order to reduce the scale of logistics and improve logistics efficiency.

\section{References}

[1] Gao Teng. Study on Logistics Efficiency in China Based on DEA [J].China Logistics \& Purchasing, 2010(6):12-15.

[2] Zhang Jianqin. Empirical Study on Evaluation of Logistics Efficiency of Provinces of China Based on DEA [J] Logistics Technology, 2013(5):31-34.

[3] Liang Wen, Lin Shan. Research of Logistics Efficiency in Anhui Province based on DEA Model [J]. Logistics Sci-Tech, 2014, (6):34-39.

[4] Tian Li. Evaluation of Efficiency of Logistics Industry in Henan Based on DEA [J] Logistics Technology, 2015(1):161-164. 